\title{
Objectifying processes: The use of geometric morphometrics and multivariate analyses on Acheulean tools
}

\author{
Paula García-Medrano ${ }^{1}$, Elías Maldonado-Garrido ${ }^{1}$, Nick Ashton ${ }^{1}$, \\ Andreu Ollé ${ }^{2,3}$
}

1. Dept. Britain, Europe and Prehistory, British Museum, Frank House, 56 Orsman Road N1 5QJ, London, U.K.

Email: Garcia-Medrano: pgarciamedrano@gmail.com; Maldonado-Garrido: emaldonadogarrido@gmail.com; Ashton: nashton@britishmuseum.org

2. Institut Català de Paleoecologia Humana i Evolució Social (IPHES), Zona educacional 4, Campus, Sescelades URV (Edifici W3), 43007 Tarragona, Spain. Email: aolle@iphes.cat

3. Àrea de Prehistòria, Universitat Rovira i Virgili (URV), Fac. Lletres, Av. Catalunya, 35, 43002 Tarragona, Spain.

\begin{abstract}
:
Nowadays, the fruitful discussion regarding the morphological variability of handaxes during the Middle Pleistocene has reached a decisive moment with the use of more accurate statistical methods, such as geometric morphometrics (GM) and multivariate analyses (MA). This paper presents a preliminary methodological approach for checking the utility of these new approaches on the analysis of the tools' shape. It goes beyond the simple description of morphology and isolates the variables which define the final morphology of a tool. We compared two Middle Pleistocene sites, Boxgrove and Swanscombe, which are morphologically very different. Then, we applied the GM analysis on 1) 2D images, with two semi-landmark distributions: 28 semi-landmarks, specially concentrated on the tip and butt, and 60 equally spaced points; and 2) on 3D models using a new software (AGMT3-D Software) including 5000 semi-landmarks. The more points used to define the tool's outline, the more accurate will be the interpretation of the variables affecting shape. On the other hand, if the semi-landmarks are localized on specific sectors of the tool, a bias is created, by concentrating on those sectors, rather than the general tool shape. The 3D models offer a new dimension on the shape analysis, as their results mean the combination of plan-shape, profileshape and the tool's topography.
\end{abstract}

Keywords: Middle Pleistocene; Acheulean; handaxes; geometric morphometrics; multivariate analyses; Boxgrove; Swanscombe

Published by the School of History, Classics and Archaeology, University of Edinburgh ISSN: 2055-0472. URL: http://journals.ed.ac.uk/lithicstudies/

Except where otherwise noted, this work is licensed under a CC BY 4.0 licence. 


\section{Introduction}

Since the early stages of prehistoric research, there have been persistent attempts to develop a common set of technological features and measures in which the morphology of different lithic assemblages could be classified and compared. These classical methods for the study of stone artefacts have led us to distinguish between different technological modes, or cultural technological groups (Clark 1996). The differences are mainly based on the combination of presence or absence of some technological markers (cores and flake systems, Large Cutting Tools or the Levallois technique) with the chronological boundaries of each site. For a long time, the aim of the study of these technological groups was the characterization of the operative chains and the determination of the final tools' typology (Boëda et al. 1990; Bordes 1961; Carbonell et al. 1992; Newcomer 1971; Wenban-Smith 1989). Nowadays, there is a focus on the morphological variability of tools and their possible origin. Traditionally, this analysis has been made using metrical approaches, quantifying the morphology by a set of discrete metric measures, and characterizing an assemblage by the distribution of these measures (Bordes 1961; Roe 1968). Nevertheless, the morphology of tools is a much more complex issue than the superficial description of measures and indices, and it should refer to the entire shape, or to global properties of the artefact, more than to local measures (Grosman et al. 2008).

GM analysis is a powerful tool for the quantitative description of shape variability within and between groups. Nevertheless, it has had two significant handicaps: the limited computing power and 3D scanning possibilities (Lycett et al. 2006; Lycett 2009; Rovner 1995); and the problems and difficulties entailed in the application of landmark or semilandmark-based methods to material cultural objects (Archer \& Braun 2010; Bretzke \& Conard 2012; Costa 2010; Eren \& Lycett 2012; Herzlinger \& Grosman 2018; Lycett \& Chauhan 2010; Lycett \& von Cramon-Taubadel 2013; McNabb 2007). The main problem, among others, has been the lack of readily identifiable, homologous landmarks on artefacts, (Lycett \& Chauhan 2010). The lack of protocols requires a comparison of methods to test which is the most appropriate to analyse the morphology of tools. Here, we have compared the results between the use of $2 \mathrm{D}$ images or $3 \mathrm{D}$ models. In addition, it is also necessary to define how many semi-landmarks are required to define accurately the tool's outline.

In the context of the Western European Acheulean Project (WEAP, Marie Skłodowska Curie IF-EF-ST Fellowship, Project ID: 748316), we have defined a common method of analysis for the study of handaxes and cleavers from several sites in the UK, France and Spain, based on a selection of technological attributes from the main traditions of lithic analysis (typological, technological, morphometrical and sequential) that are considered to be particularly significant (Garcia-Medrano in prep.). Besides, combined with this technological characterization, WEAP has used GM on 2D images and 3D models to analyse both plan and profile shapes of handaxes and cleavers.

The aim of this work is to make a preliminary methodological approach comparing the use of 28 (concentrated on tip and butt) and 60 (equally distributed) semi-landmarks, both on 2D images; and 5000 points, on 3D models. The results have been interpreted using MA. This is increasingly used to discern patterns of variability in lithic assemblages and help with their interpretation. One of the most frequently used is Principal Component Analysis (PCA). IN this case, we have applied this analysis on two of the main Middle Pleistocene sites in Britain: Swanscombe and Boxgrove.

\section{Archaeological context}

WEAP includes the analysis of handaxes and cleavers from several sites in the UK, France and Spain (La Noira, Brandon Fields, Cagny La Garenne, Elveden, Swanscombe, 
Saint Pierre-lès-Elbeuf, Menez-Dregan and Galería and TD10.1 sublevel of Gran Dolina, Atapuerca). For this paper, we have chosen two of the key British Middle Pleistocene sites: Boxgrove and Swanscombe (Figure 1). The clear association between fauna and very rich lithic assemblages, together with hominin remains attributed to Homo heidelbergensis and early Neanderthals makes them two of the key sites for interpreting the Acheulean and occupation of Britain (Conway et al. 1996; Hillson et al. 2010; Overy 1964; Roberts \& Parfitt 1999a; Schreve 2004; Stringer et al. 1998). In the last few years, the differences between them from both an occupational and technological point of view have been highlighted (McNabb et al. 2018; Moncel et al. 2015; Smith 2013). In this case, we have focused on the morphological differences between the handaxes and the methods of analysis.

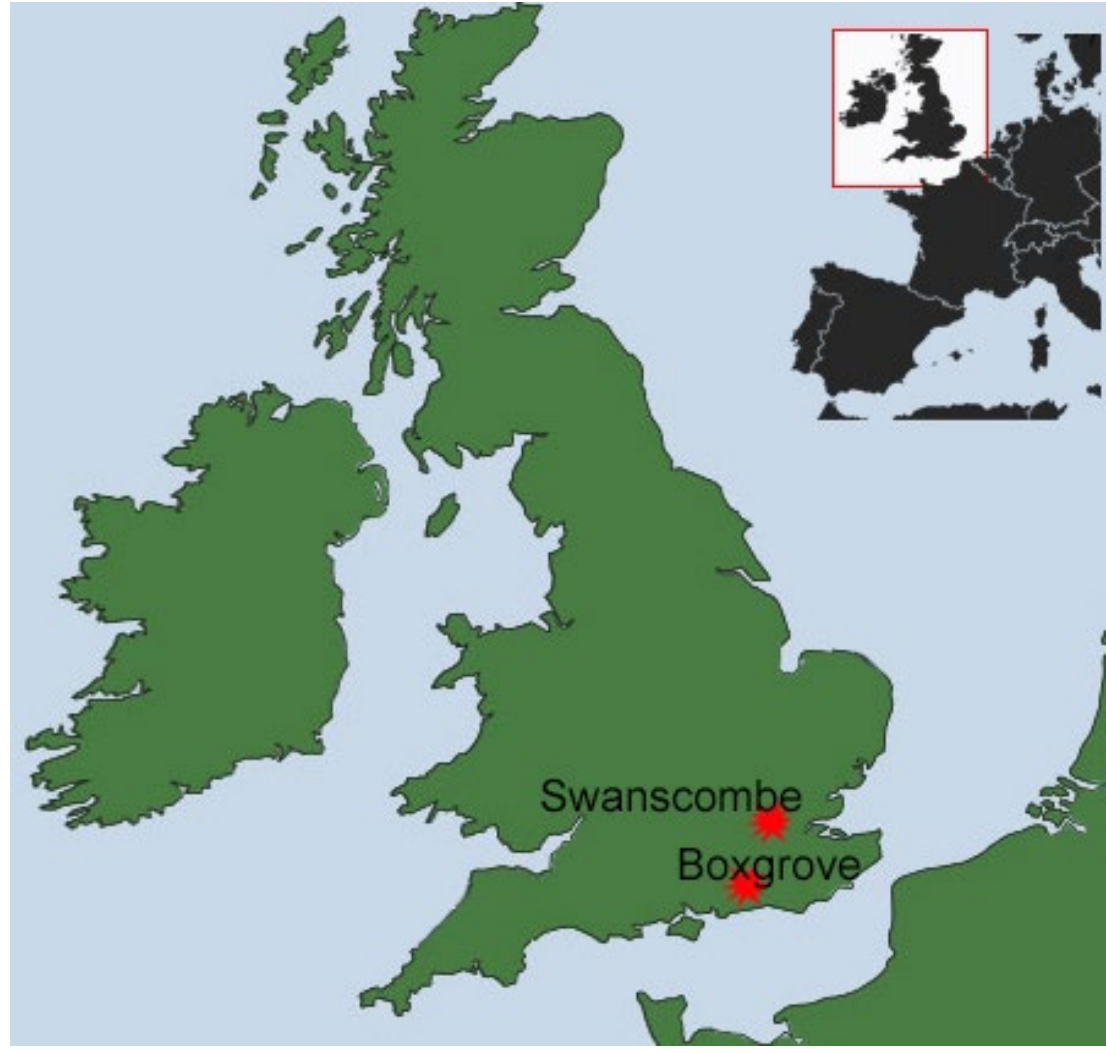

Figure 1. Location of the Boxgrove and Swanscombe sites

Boxgrove (West Sussex) is situated $7 \mathrm{~km}$ east of Chichester, at the junction between the South Downs and the present Sussex Coastal Plain. This region has been shaped by a series of marine transgressions and regressions (Roberts \& Parfitt 1999a; 1999b). The Boxgrove stratigraphic sequence was deposited on a chalk wave-cut platform that during the Middle Pleistocene was below a 75-100m cliff (Lewis \& Roberts 1999; Roberts et al. 1997). Mapping of these deposits, in relation to the solid chalk geology, indicates deposition within a semienclosed marine bay formed by the extant Portsdown and Littlehampton Anticlines (Barnes 1980). The Middle Pleistocene sediments show marine regression towards the end of an interglacial (MIS 13; Slindon Formation) and the onset of fully terrestrial conditions prior to and into the ensuing glacial (MIS 12; Eartham Formation). Using key biostratigraphic marker species the marine, intertidal and lower terrestrial units have been dated to the late ‘Cromerian’ MIS 13, 524-478ka (Roberts \& Pope 2018).

The importance of the site rests on the preservation of some of the clearest evidence for hominin presence and behaviour in Britain during the Middle Pleistocene (Parfitt et al. 2005; 2010; Pope 2002; Pope \& Roberts 2005; Roberts \& Parfitt 1999a). The Boxgrove lithic 
collection is exceptional in terms of its preservation, due to the nature of its burial and its subsequent taphonomic history, and because of the great quantity of large tools recovered, mainly handaxes (García-Medrano et al. 2019). Fauna from Boxgrove is diverse (Parfitt 1999a; 1999b) indicating a mosaic environment of open grassland alongside areas of deciduous and mixed woodland. A tibia and two incisors, assigned to Homo $c f$. heidelbergensis, physically illustrate the presence of hominins within the site's mammalian palaeo-community (Stringer et al. 1998; Stringer \& Trinkaus 1999; Trinkaus et al. 1999).

Barnfield Pit, Swanscombe (Kent), a former chalk quarry, is situated on the southern flank of the Lower Thames basin, $5 \mathrm{~km}$ east of Dartford. Deposits of gravels, sands and loams have been recorded from the site along with flint tools and Pleistocene fauna (Conway et al. 1996; Gibbard 1985). Mammalian biostratigraphy and lithostratigraphy attribute the site to the Hoxnian interglacial (MIS 11; c. 423-380 kyr BP) (Bridgland 1994; Schreve 1996; 2004). The MIS 12 glaciation diverted the course of the River Thames southwards to its present course (Bridgland 1994; Preece 1995). At Swanscombe the new course is represented by terrace deposits of sands, gravels and floodplain loams, which accumulated during MIS 11, including the Upper Middle Gravels (UMG), which are the focus of this paper (Conway et al. 1996).

The fauna from the UMG highlights a mosaic environment with open-grasslands and deciduous woodland along and around the channel margins (Schreve 1996; 2004). Three refitting skull fragments show the presence of early Neanderthals at Swanscombe (Overy 1964; Stringer, 2012; Stringer \& Gamble 1993). Alongside fossil evidence, lithic artefacts including handaxes and flake tools have also been recovered (Ashton \& McNabb 1996; Ashton et al. 1998; McNabb 2007). The association of lithics and fauna at Swanscombe has been variously interpreted as either evidence of a hominin hunting camp alongside a river channel (Waechter 1968; 1969; 1976) or scavenging of carnivore kills and natural deaths by hominins (Binford 1985). Neither interpretation has adequately assessed the taphonomy of the faunal assemblage and the role that non-human agents played in site formation and modification. Swanscombe, therefore, provides an ideal case to analyse the hominin behaviour at this location but also to produce a detailed understanding of faunal taphonomy and overall site formation processes (Smith 2013).

\section{Methodology}

While there are several morphometric approaches, landmarks-based GM is a powerful tool for the quantitative description of shape variability within and between groups (Lycett \& Chauhan 2010). It is a variant of the methods used for the quantitative study of shape and shape differences between physical objects (Herzlinger \& Grosman 2018). This approach has been used by archaeologists and is drawn from various fields in biology. It is based on a finite number of points - landmarks - that are placed on the surface of the studied items and expressed by two or three Cartesian coordinates. These landmarks should have respective points across all specimens in the sample (homology).

While in biology homology can be based on phylogenetic, developmental or functional considerations, objects of material culture lack such readily identifiable homologous landmarks (Lycett \& Chauhan 2010; Okumura \& Araujo 2018). For that, the study of archaeological artefacts uses semi-landmarks, which are localised according a consistent geometric positioning of the tools (Bookstein 1997; Dryden \& Mardia 1998). Nevertheless, there is a lack of a single protocol to define the outlines and how many points are necessary to analyse accurately the morphology of handaxes and cleavers. Some researchers use different quantities of semi-landmarks (equally spaced or concentrated in specific tool's sectors) or 
landmarks at specific points (Costa 2010; Lycett \& von Cramon-Taubadel 2013; McNabb et al. 2018).

We have chosen thirty handaxes per site, with different sizes and shapes (Figure 2). All the materials have been photographed using a Nikon D3200, and keeping a $90^{\circ}$ angle between the camera and the instrument. The tools have been oriented firstly, according to their maximum length; and secondly with the upper face as the dorsal face (in the case of flakes) or the face with major convexity. All the photographs have been saved in .NEF and .jpg formats, with an image size of 6016x4000 pixels. The 3D scans have been made using a Structured Laser Scan (HDI Advance Scan) and the Flexscan software. The 3D models have been saved as .ply format and extracted using the Artifact 3D Software (Grosman et al. 2008).

So, in this paper, we have explored two different approaches for analysing morphology with 2D images: 1) 60 equally spaced points along the whole outline of the tool (Figure 3a) and 2) 28 points with special concentrations on tip and butt (Figure 3b). The 60 equally spaced points have been generated automatically with the tpsDig2 software (Rohlf 2009).

On the other hand, the extraction of the 28 points has been created with a standard web of points and then superimposed onto the images, according to the length of each tool. This has been made using Autocad Software. The points have then been extracted using also tpsDig2. Once the extraction of coordinate data has been made, the pieces have been oriented according to their maximum length, beginning from the tip. In both cases, the starting point has been manually digitized. The XY coordinates of the different points per specimen have been saved in .NTS file, and then exported to PAST software (Paleontological Statistics) (Hammer et al. 2001). A 2D Procrustes superimposition of the XYoutline coordinate data has been performed, which scaled, rotated, and translated the XY data, bringing all handaxe outlines to a standardized size, orientation, and position before subsequent analysis (Figure 4). In this way, the differences in landmarks' can be attributed exclusively to shape differences between different objects.

In contrast, for performing the landmarks-based GM shape analysis on 3D models we have used the open access Artifact GeoMorph Toolbox 3D (AGMT3-D). This is a software designed specifically to use on archaeological artefacts. It has been written using the Matlab programming language. AGMT3-D consists of a data-acquisition procedure for automatically positioning 3D models in space and fitting them with grids of 3D semi-landmarks. In fact, each point of the grid consists of two semi-landmarks, one placed on each artefact face, so that a grid of $50 \times 50$ provides 5000 landmarks (Figure 3c). The top and bottom latitudes capture the exact 3D outline of the artefact's distal and proximal ends. Thus, this protocol provides a list of landmarks that accurately expresses the artefact's volumetric configuration. It also provides a number of analytical tools and procedures that allow the processing and statistical analysis of the data (Herzlinger \& Grosman 2018).

The multivariate outline data obtained has been projected into two dimensions so that the underlying shape variables could be qualitatively examined and compared. In order to interpret the meaning of the PCA results from a morphological perspective, Procrustes superimposed shape data have been examined utilizing thin-plate splines to facilitate visualization of shape changes from the group mean along relative warp (i.e., principal component) axes (Hammer \& Harper 2006). By examining the morphological deformations and XY plots of specimens from the PCA scatters, it has been possible to interpret the shape variation by itself. The PCA graph includes the warps' tool (representing the tools' morphology) on the maximum value of each axis. Colour coding remark the landmarks that vary the most on the shape trend described on positive and negatives scores of PC1 and PC2. 


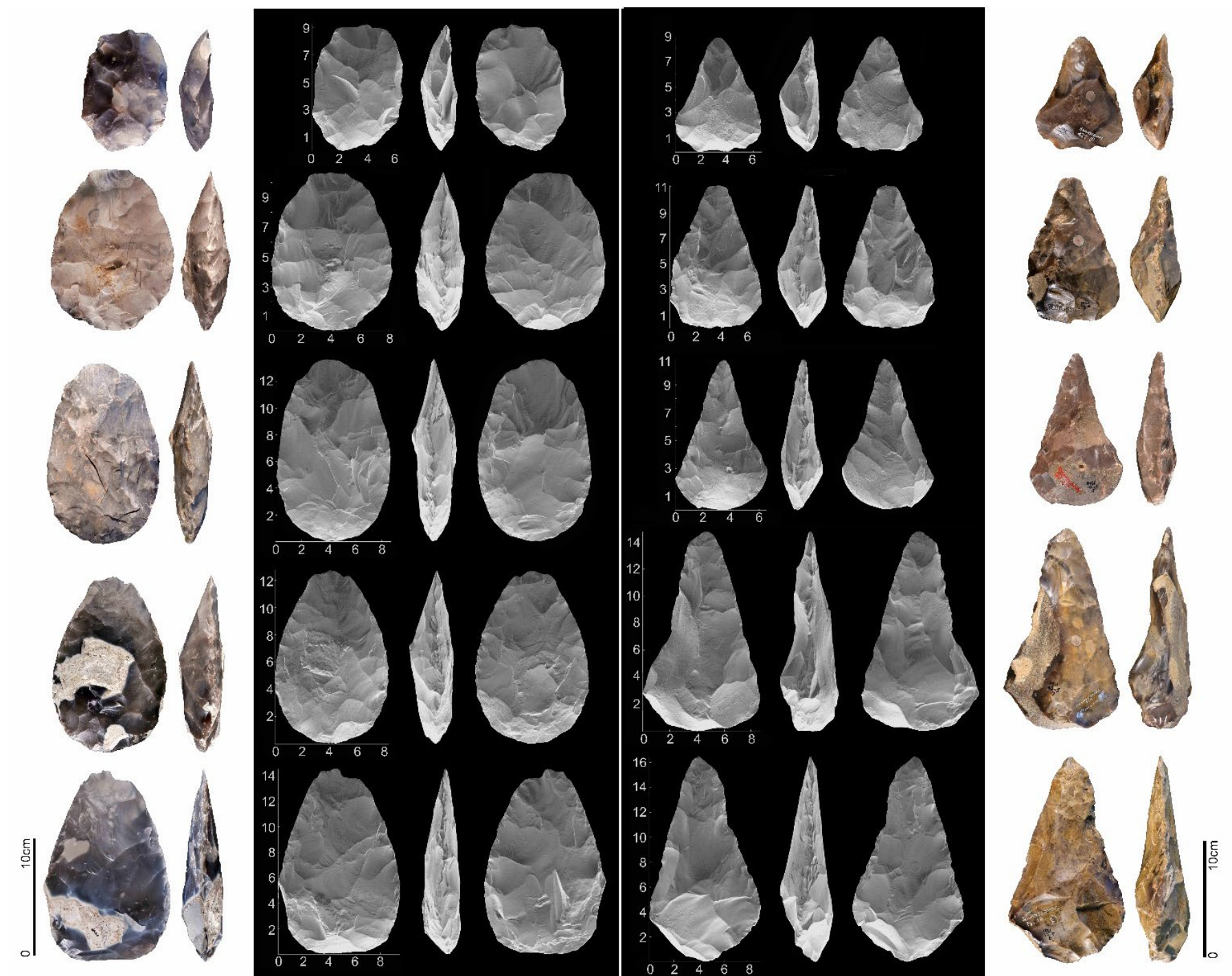

Figure 2. Examples of handaxes from Boxgrove Q1B Unit 4 (left) and Swanscombe-UMG (right) used with this methodological approach. The 3D images have been extracted using Artifact3-D Software (Grosman et al., 2008). 

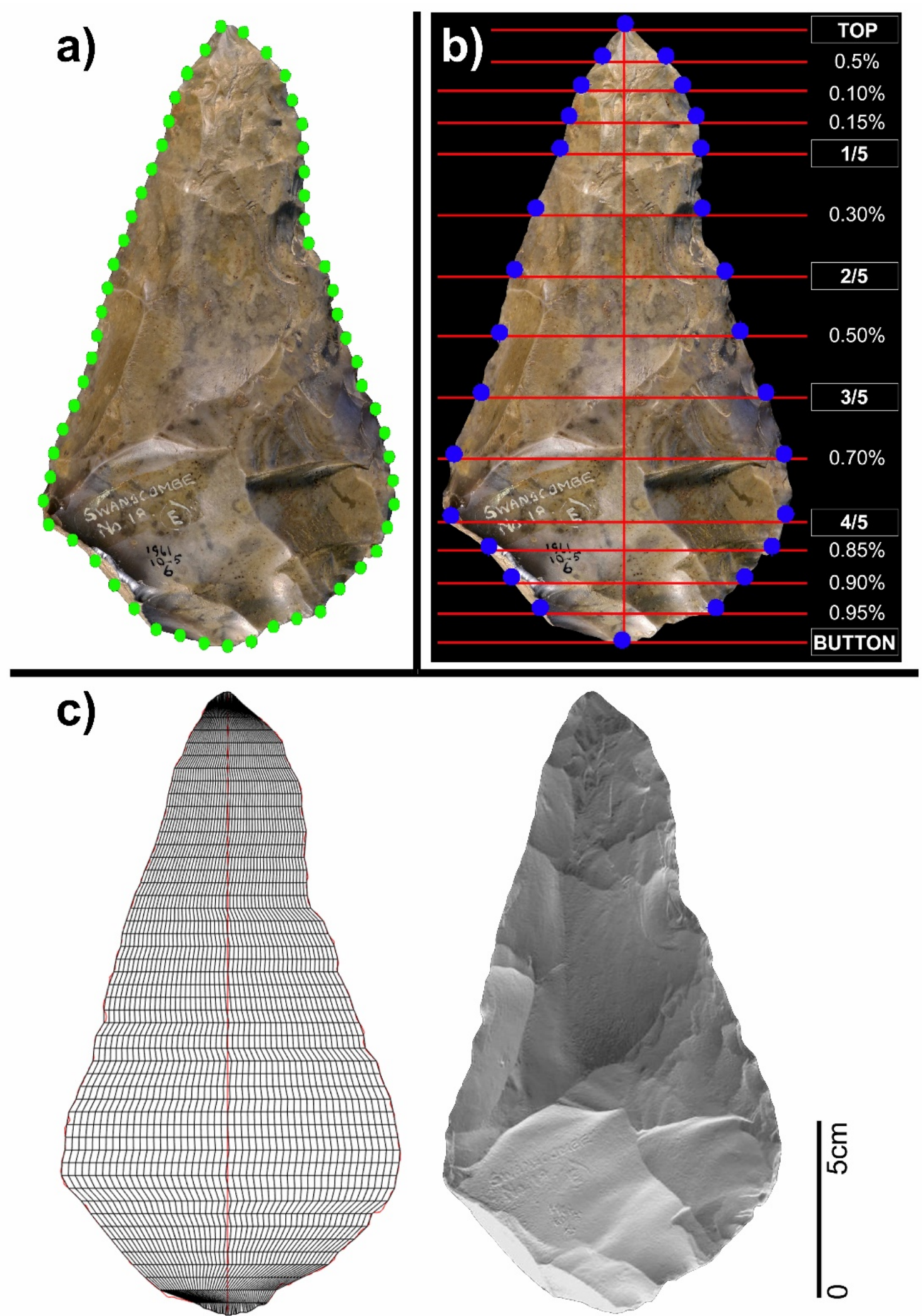

Figure 3. Three morphometrical approaches to the analysis of the morphological variability of handaxes using 2D images (a, b) and 3D models (c). a) 60 equally spaced points, b) 28 semi-landmarks, specially concentrated on tips and proximal parts, and c) 5000 points defining outlines and tool surfaces. 


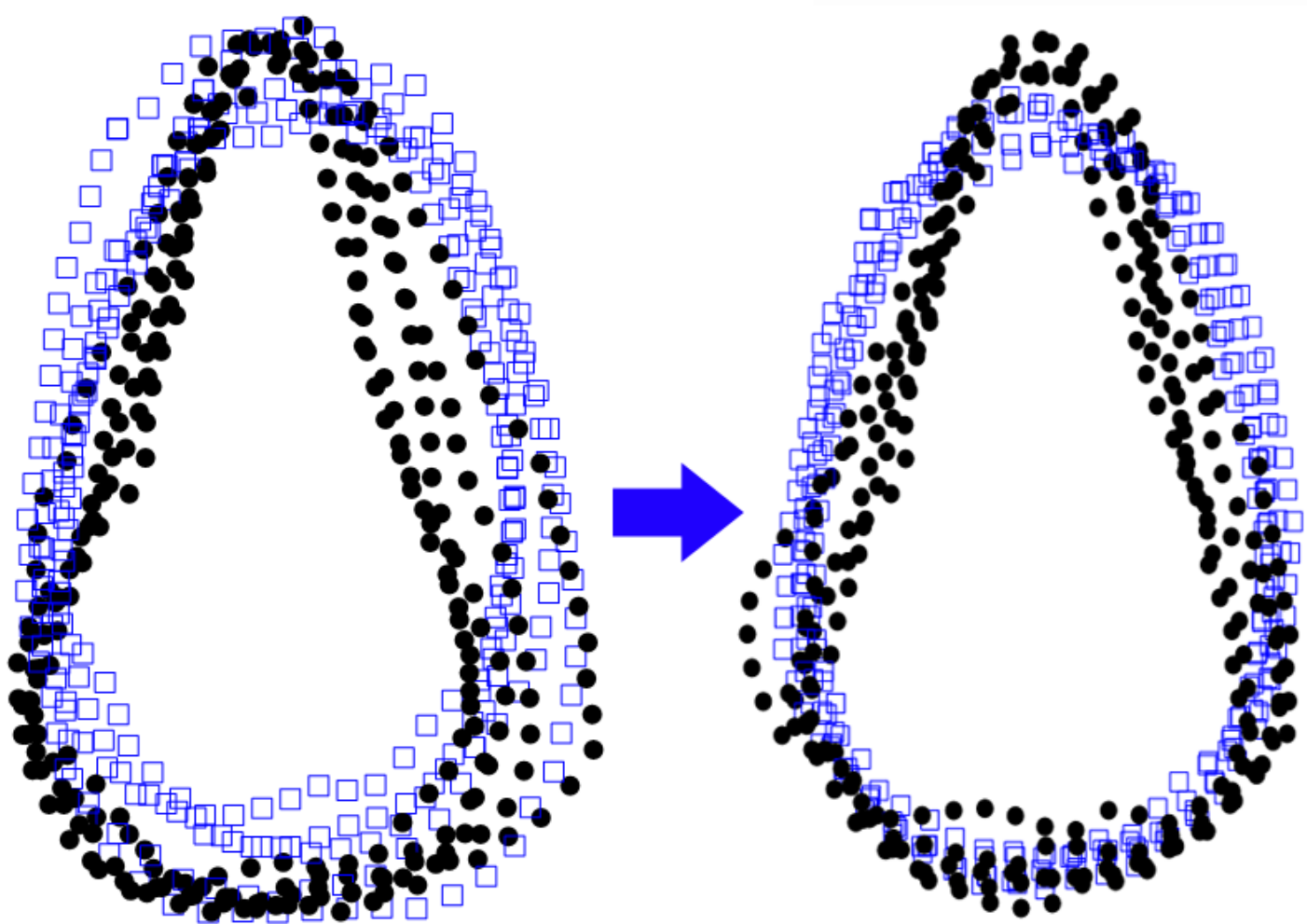

Figure 4. Procrustes superimposition process removes size, translates, and rotates (i.e., orientation) the outlines from the original shape data. Original outline data (left) vs. Procrustes aligned data (right). These images correspond with the 60 equally spaced points outlines of handaxes from the Swanscombe (black dots) and Boxgrove (blue squares).

Those morphological tendencies lack the size effect and compare the different tools within a site or between different sites. In addition, the derived principal component scores has also permitted application of other quantitative tests of multivariate equality of means between the groups (Costa 2010; Herzlinger \& Grosman 2018).

\section{Results}

With the outlines defined using 2D images with 28 points, specially located on the tool's tip and butt, the PC1 explains 56.70\% of the morphological variability Boxgrove and Swanscombe-UMG handaxes (Figure 5a), showing a clear division between wider oval shapes or wider bases with pointed tips. And the second factor, explaining the $16.81 \%$ of their variability of those samples, represent nearly the same pattern that the first PC, but concentrated mainly on bases: wider bases vs. narrow ones. So, this approach clearly associates the tool's morphological variability to the shape on tips and butts.

If we define the handaxes' outlines using 60 points, equally distributed, the morphological variability of handaxes is mainly explained by the combination of the two Principal Components: PC1 (51.09\%) and PC2 (17.52\%) (Figure 5b). So, despite the clear dependence on the features of the tip vs butt (PC1), there is a second factor (PC2) which contribute to the morphological variability of tools: the distribution of the edges, either convergent or with a clear tendency to parallel edges (Figure 5b).

Nevertheless, according to the non-parametric Mann-Whitney U test, in both cases only the PC1 has statistically significant effect in the morphological differences between the handaxes from those two sites, PC1 (28 points $\mathrm{p}=0.0001$ and 60 points $\mathrm{p}=0.0001$ ) and PC2 ( 28 points $\mathrm{p}=0.66$ and 60 points $\mathrm{p}=0.99$ ). 


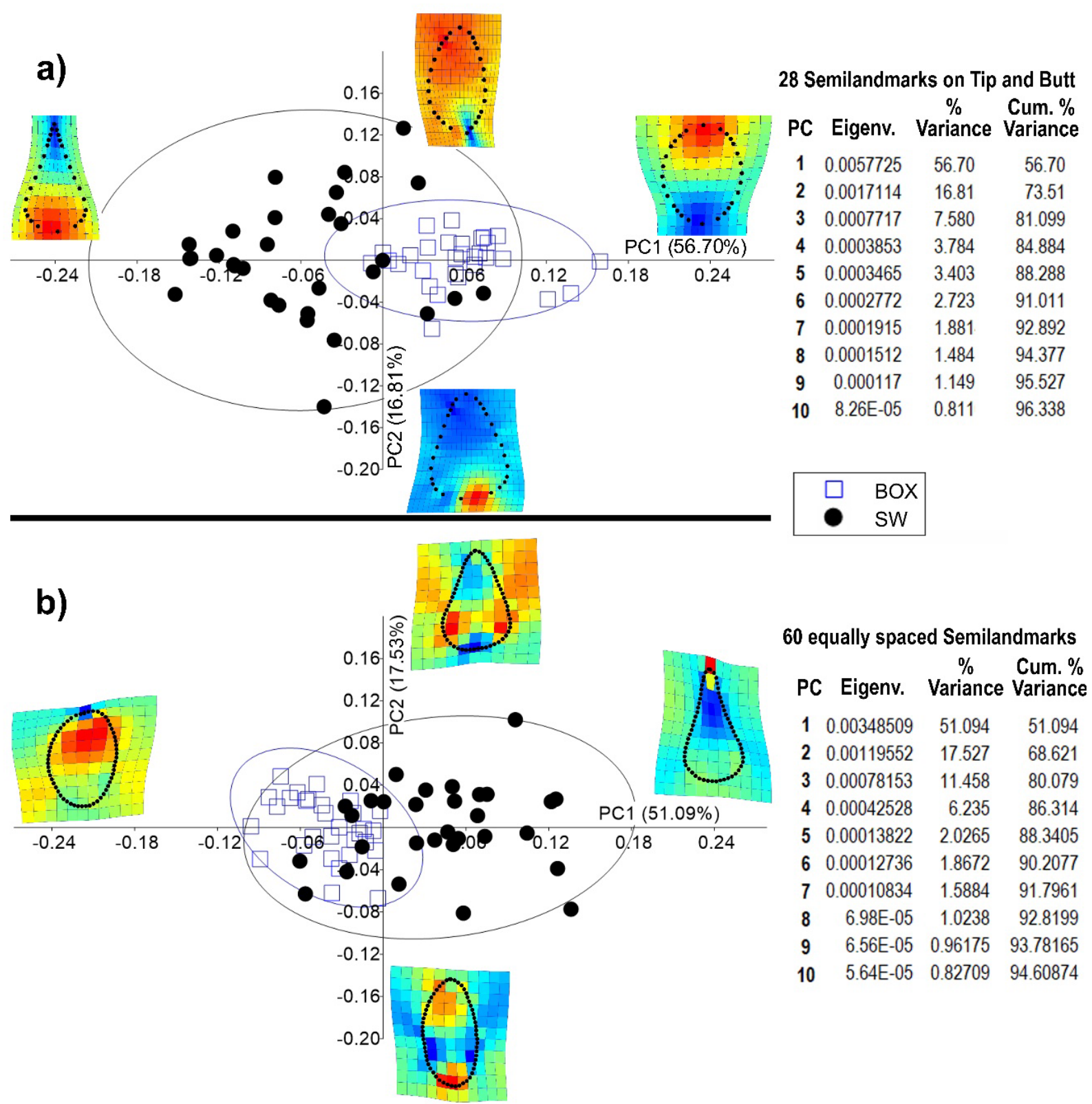

Figure 5. Principal components scatter plots of handaxes from Boxgrove (blue square) and Swanscombe (Black dots). Outlines on 2D images, made on 28 semi-landmarks (upper), and on 60 equally spaced semi-landmarks (lower) with their percentages of cumulative variance of each graph.

In addition, using the 3D models to analyse variability and creating a web of 5000 points, using not only outlines but also surfaces and topography, it shows how most of the variability is expressed for the two first principal components: PC1 (35.37\%) and PC2 (10.76\%). These results are very similar to those explained by the 60 equally spaced points. The difference between them is the main feature represented within these PCs. As in the two previous cases, PC1 represents the oval shapes vs pointed tips. Nevertheless, the major variability is concentrated only from the mid part of the object to the tip. On the other hand, the second component refers to the changes in the proximal part of the tool, in combination with changes of the tool's thickness (Figure 6). In this case, it shows how the thickest tools are more pointed and the thinner ones more oval through using the combination of 3D models planshape analysis and profile shape, to get the most accurate interpretation of the data. 


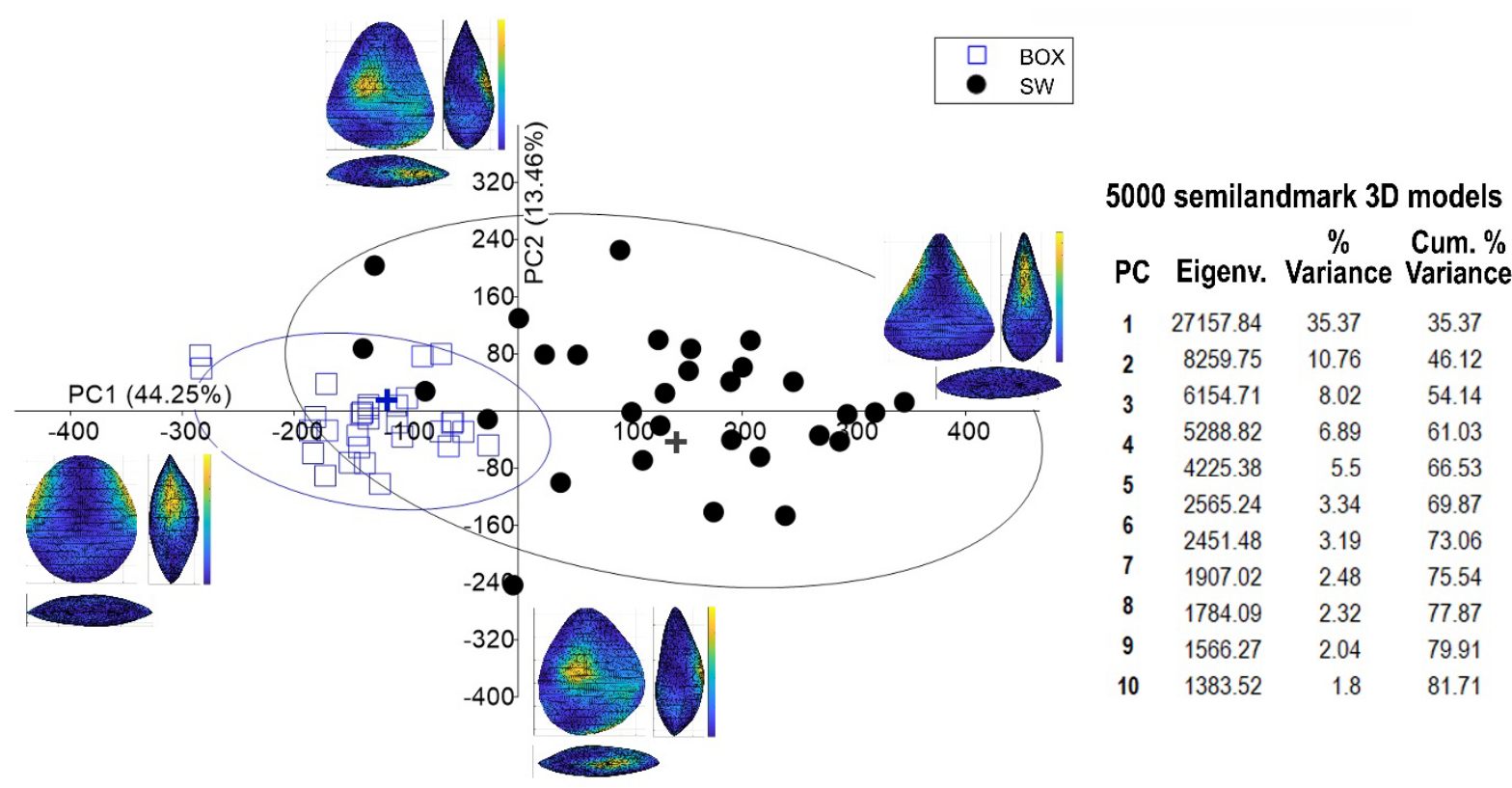

Figure 6. Principal components scatter plots of handaxes from Boxgrove (blue square) and Swanscombe (Black dots). Outlines on 3D models, made on 5000 semi-landmarks, with their percentages of cumulative variance. The ellipses are 90\% confidence ellipses. It includes the warps' tool, representing the morphology. Colour coding represents the landmarks that vary the most on the shape trend described on positive and negatives scores of the PC1 and PC2. Two crosses represent the mean shapes of each group.

In addition, if we apply a Wilcoxon Rank-Sum test on inter-point distances between group means points (Figure 6 ) the results show that the mean shapes between Boxgrove and Swanscombe handaxes are significantly different, (ranksum=2330, n1=30, n2=30, $\mathrm{p}=<0.01$ ).

\section{Discussion and conclusions}

In recent years there has been increasing use of statistically robust methods in archaeological studies and experiments to characterize and define the morphologies of Acheulean handaxes. Despite the significance of these tools, there is no one protocol based on experimental tests to choose the most suitable way to analyse morphology.

In this case, we have compared two Middle Pleistocene British sites: Boxgrove and Swanscombe. Boxgrove has 'classic' oval bifaces and those from Swanscombe have more pointed shapes (Figure 2). According to our results, a low number of points or the concentration of those on selected parts (in this case, tip and butt), simplify the origin of the morphological differences or create a tendency to concentrate the analysis on these specific parts. Besides, the equally distribution of points generates more information along the whole perimeter of tools, allowing us to include other aspects such as the distribution of edges, something clearly related with the width effect, localisation of the widest point and the Elongation index, maximum length (L)/maximum width (m). And this aspect has been crucial in the traditional interpretation of those samples by authors as Bordes (1961) and Roe (1968).

Both 60 equally spaced points on 2D images and 5000 points on 3D models are very useful to interpret and analyse the factors which explain the morphological variability of tools, independent of their size. Nevertheless, increasing the number of points, there are substantial changes to take into account. PCA provides a small number of independent (noncorrelated) linear combinations (principal components) of a set of measured variables that capture as much of the variability in the original variables as possible. By default, if the number of variables (semi landmarks) $p$ is smaller than the number of observations (artifacts) $n$, the analysis produces $p$ principal components. If the number of observations is higher, than 
n-1 principal components are produced. The principal components are ranked so that each subsequent principal component explains less variability than its former one. The proportions of variability of each PC (and hence also the cumulative explained variability) is calculated by dividing the PC's eigenvalue by the sum of eigenvalues of all the PCs. For example, if the 3D dataset consists of 60 artifacts and 15000 landmarks coordinates (5000 landmarks $\times 3$ dimensions), then the proportion of explained variability of each PC should be calculated by dividing each PC's eigenvalue by the sum of the eigenvalues of 59 PCs. So, there are differences in the number of PCs and differences in the percentage of variability represented by them on each case (Figure 7). As less number of points are considered, more variability is represented by the first PCs. Nevertheless, in the case of the outlines made using 28 and 60 points, the $90 \%$ of the variability is explained by the first 6 principal components. By the contrary, in the case of 5000 points, the $90 \%$ of variability is explained in the first 19 principal components.

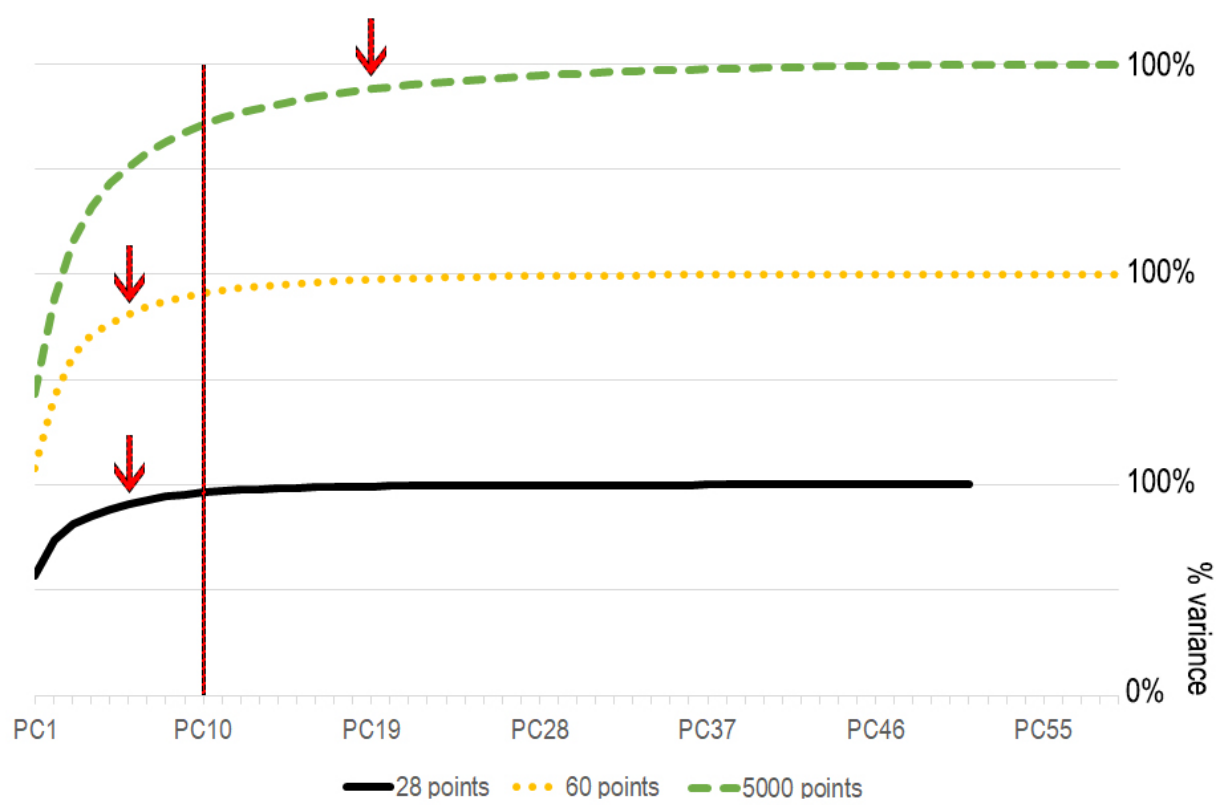

Figure 7. Cumulative variability chart (28 points, 60 points, 5000 points). The red line marks the first ten principal components. The red arrows show where the PCs represents more than $90 \%$ of the variability.

The resulting information is complementary between these approaches. As the 60 points only define the outline of pieces (contour), the resulting information only refers to that aspect: the butt and tip and the delineation of the edges. If any additional information is required, e.g., the thickness of tools, there is a need to conduct a new analysis of the profile shape. With the 3D models the whole information is recorded, so the 5000 points cover the whole surface of the tool, analysing at the same time the plan and the profile shapes. This is crucial because the thickness of tools is one of the factors that has stronger variation through the shaping process and is clearly associated with the thinning process. In our case, it is much more significant because the thickness is clearly correlated with the distal shape.

So, as we have seen the localisation of points on specific sectors of the tools, generates a bias in the results, whereas more points provide a better record. But even nowadays, many of the researchers do not have a 3D scanner available. If this is the case, the 2D images can be used to analyse the tool's morphological variability. But at least, 60 equally spaced points are needed to get an accurate analysis of the tool's shape. It is also important to remark that for a complete description of the factors that contribute to the shape variation, not only should the plan shape be considered, but also the profile of tools. So, the process must be made twice. 
On the other hand, working with 3D models, a web of 5000 semi-landmarks will record the maximum morphology of tools, including plan-shape, surface topography and profile shape. Through this method, the PCA made on the resulting coordinate points provides a complete view of all the factors that contribute to the shape variation between several tools or several groups of tools.

\section{Acknowledgements}

P.G.M. has fellowship from the European Union's Horizon 2020 research and innovation programme under the Marie Sklodowska-Curie grant agreement N. 748316. This study has been developed at the Dpt. Britain, Europe and Prehistory (British Museum) at the Franks House. The University of Bradford and Dr. Adrian Evans, throughout the "Fragmented Heritage AHRC Project", have led us the scanner to work with. We feel really thankful with the Hebrew University of Jerusalem, Dr. Leore Grosman and Antoine Miller, who have helped us with the Artifact3-D and AGMT3-D softwares.

\section{References}

Archer, W. \& Braun, D.R. 2010, Variability in bifacial technology at Elandsfontein, Western cape, South Africa: A geometric morphometric approach. Journal of Archaeological Science, 37(1): 201-209. doi:10.1016/j.jas.2009.09.033

Ashton, N. \& McNabb, J. 1996, The flint industries from the Waechter excavations. In: Excavations at Barnfield Pit, Swanscombe, 1968-72, (Conway, B., McNabb, J. \& Ashton, N. Eds.), British Museum Occasional Paper Vol. 125, British Museum Press, London: p. 53-66.

Ashton, N., Lewis, S.G. \& Parfitt, S. (Eds.) 1998, Excavations at the Lower Palaeolithic Site at East Farm, Barnham, Suffolk 1989-94. British Museum Occasional Paper Vol. 125, British Museum Press, London, 305 p.

Barnes, R.S.K. 1980, Coastal Lagoons. Cambridge University Press, Cambridge, 120 p.

Binford, L.R. 1985, Human Ancestors: changing views of their behaviour. Journal of Anthropological Archaeology, 4(4): 292-327. doi:10.1016/0278-4165(85)90009-1

Boëda, E., Geneste, J.-M. \& Meignen, L. 1990, Identification de chaînes opératoires lithiques du Paléolithique ancien et moyen. Paléo, Revue d'Archéologie Préhistorique, 2(1): 4380. (in French) ("Identification of lithic chaînes opératoires of the Old and Middle Palaeolithic”) doi:10.3406/pal.1990.988

Bookstein, F.L. 1997, Landmark methods for forms without landmarks: morphometrics of group differences in outline shape. Medical Image Analysis, 1(3): 225-243.

Bordes, F. 1961, Typologie du Paléolithique Ancien et Moyen. CNRS Editions, Paris, 216 p. (in French) (“Old and Middle Palaeolithic typology”)

Bretzke, K. \& Conard, N.J. 2012, Evaluating morphological variability in lithic assemblages using 3D models of stone artifacts. Journal of Archaeological Science, 39(12): 37413749. doi:10.1016/j.jas.2012.06.039

Bridgland, D.R. 1994, Quaternary of the Thames. Chapman and Hall, London, 460 p.

Carbonell, E., Mosquera, M., Ollé, A., Rodríguez, X.P., Sala, R., Vaquero, M. \& Vergés, J.M. 1992, New elements of the logical analitic system. Cahier Noir, 6, 61 p. 
Clark, J.D. 1996, The Acheulian industrial complex in Africa and elsewhere. In: Integrative Paths to the Past: Palaeoanthropological Advances in Honor of F. Clark Howell (Corruccini, R.S. \& Ciochon, R.L., Eds.), Englewood Cliffs, Prentice Hall Publishers, New Jersey: p. 451-469.

Conway, B., McNabb, J. \& Ashton, N. 1996, Excavations at Barnfield Pit, Swanscombe, 1968-72. British Museum Press, London, 265 p.

Costa, A.G. 2010, A Geometric Morphometric assessment of Plan shape in bone and stone Acheulean bifaces from the Middle Pleistocene site of Castel di Guido, Latium, Italy. In: New Perspectives on Old Stones: Analytical Approaches to Paleolithic Technologies (Lycett, S.L. \& Chauhan, P.R.E., Eds), Springer, New York: p. 23-41. doi:10.1007/9781-4419-6861-6_2

Dryden I.L. \& Mardia K.V. 1998, Statistical shape analysis. Wiley, Chichester, 347 p.

Eren, M.I. \& Lycett, S.J. 2012, Why Levallois? A morphometric comparison of experimental 'preferential' Levallois flakes versus debitage flakes. PLoS One, 7(1): e29273. doi:10.1371/journal.pone.0029273

García-Medrano, P., A. Ollé, N. Ashton \& Roberts M.B. 2019, The Mental Template in Handaxe Manufacture: New Insights into Acheulean Lithic Technological Behavior at Boxgrove, Sussex, UK. Journal of Archeological Method and Theory, 26(1): 396-422. doi:10.1007/s10816-018-9376-0

Gibbard, P. 1985, The Pleistocene History of the Middle Thames Valley. Cambridge University Press, Cambridge, 168 p.

Grosman, L., Smikt, O. \& Smilansky, U. 2008, On the application of 3-D scanning technology for the documentation and typology of lithic artifacts. Journal of Archaeological Science, 35(12): 3101-3110. doi:10.1016/j.jas.2008.06.011

Hammer, Ø. \& Harper, D.A.T. 2006, Paleontological Data Analysis. Malden. Blackwell Publishing, Oxford, 368 p.

Hammer, Ø., Harper, D.A. \& Ryan, P.D. 2001, PAST: Paleontological statistics package for education and data analysis. Paleontologia Electronica, 4(1): 4-9. URL: http://palaeoelectronica.org/2001_1/past/issue1_01.htm

Herzlinger, G. \& Grosman, L. 2018, AGMT3-D: A software for 3-D landmarks-based geometric morphometric shape analysis of archaeological artifacts. PLoS ONE, 13(11): e0207890. doi:10.1371/journal.pone.0207890

Hillson, S.W., Parfitt, S.A., Bello, S.M., Roberts, M.B. \& Stringer, C.B. 2010, Two hominin incisor teeth from the middle Pleistocene site of Boxgrove, Sussex, England. Journal of Human Evolution, 59(5): 493-503. doi:10.1016/j.jhevol.2010.06.004

Lewis, S.G., Roberts, C.L. 1999, Location of buried cliff-line using resistivity methods. In: Boxgrove: a Middle Pleistocene Hominid Site at Eartham Quarry, Boxgrove, West Sussex (Roberts, M.B. \& Parfitt, S., Eds.), English Heritage, London: p. 37-41.

Lycett, S.J. 2009, Quantifying transitions: Morphometric approaches to Palaeolithic variability and technological change. In: Sourcebook of Paleolithic Transitions: Methods, Theories, and Interpretations (Camps, M. \& Chauhan, P., Eds.), Springer, New York: p. 79-92. doi:10.1007/978-0-387-76487-0_5

Lycett, S.J. \& Chauhan, P.R. 2010, Analytical approaches to Palaeolithic technologies: An introduction. In: New Perspectives on Old Stones: Analytical Approaches to Paleolithic 
Technologies (Lycett, S.J., Chauhan, P.R., Eds.), Springer, New York: p. 1-22. doi:10.1007/978-1-4419-6861-6_1

Lycett, S.L. \& von Cramon-Taubadel, N. 2013, A 3D morphometric analysis of surface geometry in Levallois cores: patterns of stability and variability across regions and their implications. Journal of Archaeological Science, 40(3): 1508-1517. doi:10.1016/j.jas.2012.11.005

Lycett, S.J., von Cramon-Taubadel, N. \& Foley, R.A. 2006, A crossbeam co-ordinate caliper for the morphometric analysis of lithic nuclei: a description, test and empirical examples of application. Journal of Archaeological Science, 33(6):847-861. doi:10.1016/j.jas.2005.10.014

McNabb, J. 2007, The British Lower Palaeolithic: Stones in Contention. Routledge, London, $448 \mathrm{p}$.

McNabb, J., Cole, J. \& Hoggard, C.S. 2018, From side to side: Symmetry in handaxes in the British Lower and Middle Palaeolithic. Journal of Archaeological Science: Reports, 17: 293-310. doi:10.1016/j.jasrep.2017.11.008

Moncel, M. H., Ashton, N., Lamotte, A., Tuffreau, A., Cliquet, D., \& Despriée, J. 2015, North-west Europe early Acheulian. Journal of Anthropological Archaeology, 40: 302331. doi:10.1016/j.jaa.2015.09.005

Newcomer, M.H. 1971, Some quantitative experiments in handaxe manufacture. World Archaeology, 3(1): 85-104. doi:10.1080/00438243.1971.9979493

Okumura, M. \& Araujo, A.G.M. 2019. Archaeology, biology and borrowing. A critical examination of GM in Archaeology. Journal of Archaeological Science, 101: 149-158. doi:10.1016/j.jas.2017.09.015

Overy, C.D. (Ed.) 1964, The Swanscombe Skull: a Survey of Research on a Pleistocene Site. Royal Anthropological Institute. Occasional Paper No. 20. Proceedings of the Prehistoric Society, 32: 367-368. doi:10.1017/S0079497X00014602

Parfitt, S. 1999a, Mammalia. In: Boxgrove: a Middle Pleistocene Hominid Site at Eartham Quarry, Boxgrove, West Sussex (Roberts, M.B. \& Parfitt, S., Eds.), English Heritage, London: p. 197-290.

Parfitt, S. 1999b, Palaeontology. In: Boxgrove: a Middle Pleistocene Hominid Site at Eartham Quarry, Boxgrove, West Sussex (Roberts, M.B. \& Parfitt, S., Eds.), English Heritage, London: p. 157-196.

Parfitt, S.A., Ashton, N.M., Lewis, S.G., Abel, R.L., Coope, G.R., Field, M.H., Gale, R., Hoare, P.G., Larkin, N.R., Lewis, M.D., Karloukovski, V., Maher, B.A., Peglar, S.M., Preece, R.C., Whittaker, J.E., Stringer, C.B. 2010, Early Pleistocene human occupation at the edge of the boreal zone in northwest Europe. Nature, 466: 229-233. doi:10.1038/nature09117

Parfitt, S.A., Barendregt, R.W., Breda, M., Candy, I., Collins, M.J., Coope, G.R., Durbidge, P., Field, M.H., Lee, J.R., Lister, A.M., Mutch, R., Penkman, K.E.H., Preece, R.C., Rose, J., Stringer, C.B., Symmons, R., Whittaker, J.E., Wymer, J.J. \& Stuart, A.J. 2005, The earliest record of human activity in northern Europe. Nature, 438: 1008-1012. doi:10.1038/nature04227

Pope, M. 2002. The Significance of Biface-rich Assemblages: an Examination of the Behavioural Controls on Lithic Assemblage Formation in the Lower Palaeolithic. 
Doctoral Thesis at the Department of Archaeology, University of Southampton, UK, $350 \mathrm{p}$.

Pope, M. \& Roberts, M.B. 2005, Observations on the relationship between Palaeolithic individuals and artefact scatters at the Middle Pleistocene site of Boxgrove, UK. In: The Hominid Individual in Context: Archaeological Investigations of Lower and Middle Palaeolithic Landscapes, Locales and Artefacts (Gamble, C. \& Porr, M., Eds.), Routledge, London, 456 p.

Preece, R.C. (Ed.) 1995, Island Britain: a Quaternary Perspective. The Geological Society Special Publication Vol. 96, University of Cambridge, UK, 280 p.

Roberts, M.B. \& Parfitt, S. (Eds) 1999a, Boxgrove: a Middle Pleistocene Hominid Site at Eartham Quarry, Boxgrove, West Sussex. English Heritage, London, 463 p.

Roberts, M.B. \& Parfitt, S. 1999b, Human modification of faunal remains. In: Boxgrove: a Middle Pleistocene Hominid Site at Eartham Quarry, Boxgrove, West Sussex (Roberts, M.B. \& Parfitt, S., Eds.), English Heritage, London: p. 395-414.

Roberts, M.B., Parfitt, S.A., Pope, M. \& Wenban-Smith, F.F. 1997, Boxgrove, West Sussex: rescue excavations of a Lower Palaeolithic landsurface (Boxgrove Project B 1989-91). Proceedings of the Prehistoric Society, 63: 303-358. doi:10.1017/S0079497X00002474

Roberts, M., \& Pope, M. 2018, The Boxgrove wider area project. Mapping the early Middle Pleistocene deposits of the Slindon Formation across the Coastal Plain of West Sussex and eastern Hampshire. Spoilheap monograph 15, Lavenham Press, Suffolk, 193 p.

Roe, D. 1968, British lower and middle Palaeolithic handaxe groups. Proceedings of the Prehistoric Society, 34: 1-82. doi:10.1017/S0079497X00013840

Rohlf, F.J. 2009, TpsDig2 (version 2.0). Department of Ecology and Evolution. State University of New York at Stony Brook. http://life.bio.sunysb.edu/morph/morphmet/tpsdig2w32.exe

Rovner, I. 1995, Complex measurements made easy: Morphometric analysis of artefacts using Expert Vision Systems. In: Computer Applications and Quantitative Methods in Archaeology 1993 (Wilcock, J. \& Lockyear, K., Eds.), British Archaeological Reports, Oxford: p. 31-37.

Schreve, D.C. 1996, The mammalian fauna from the Waechter excavations, Barnfield Pit Swanscombe. In: Excavations at Barnfield Pit Swanscombe, 1968-72 (Conway, B., Ashton, N. \& McNabb, J., Eds.), British Museum Occasional Paper Vol. 94, London: p.149-162.

Schreve, D.C. 2004, The mammalian fauna of Barnfield Pit, Swanscombe, Kent. In: The Quaternary Mammals of Southern and Eastern England (Schreve, D.C., Ed.), Quaternary Research Association, London: p. 29-48.

Smith, G.M. 2013, Taphonomic resolution and hominin subsistence behaviour in the Lower Palaeolithic: differing data scales and interpretive frameworks at Boxgrove and Swanscombe (UK). Journal of Archaeological Science, 40: 3754-3767. doi:10.1016/j.jas.2013.05.002

Stringer, C.B. 2012, The status of Homo heidelbergensis (Schoetensach 1908). Evolutionary Anthropology: Issues, News, and Reviews, 21: 101-107. doi:10.1002/evan.21311

Stringer, C. \& Gamble, C. 1993, In Search of the Neanderthals. Thames and Hudson, London: 247 p. 
Stringer, C. \& Trinkaus, E. 1999, The human tibia from Boxgrove. In: Boxgrove: a Middle Pleistocene Hominid Site at Eartham Quarry, Boxgrove, West Sussex (Roberts, M.B. \& Parfitt, S., Eds.), English Heritage, London: p. 420-421.

Stringer, C.B., Trinkaus, E., Roberts, M.B., Parfitt, S.A. \& Macphail, R.I. 1998, The Middle Pleistocene human tibia from Boxgrove. Journal of Human Evolution 34(5): 509-547. doi:10.1006/jhev.1998.0215

Trinkaus, E., Stringer, C.B., Ruff, C.B., Hennessy, R.J., Roberts, M.B. \& Parfitt, S.A. 1999, Diaphyseal cross-sectional geometry of the Boxgrove 1 Middle Pleistocene human tibia. Journal of Human Evolution, 37(1): 1-25. doi:10.1006/jhev.1999.0295

Waechter, J. 1968, Swanscombe 1968. Proceedings of the Royal Anthropological Institute of Great Britain and Ireland 68: 53-61. doi:10.2307/3031707

Waechter, J. 1969, Swanscombe 1969. Proceedings of the Royal Anthropological Institute of Great Britain and Ireland 69: 83-95. doi:10.2307/3031747

Waechter, J. 1976, Man Before History. Elsevier, London: 150 p.

Wenban-Smith, F.F. 1989, The use of canonical variates for determination of biface manufacturing technology at Boxgrove Lower Paleolithic site and the behavioural implications of this technology. Journal of Archaeological Science, 6(1): 17-26. doi:10.1016/0305-4403(89)90053-8 